\title{
Shadow over abdomen
}

\author{
Devdeep Mukherjee, Sajit Nedungadi
}

Neonatal Intensive Care Unit, St Mary's Hospital

\section{Correspondence to} Dr Devdeep Mukherjee, doc.devdeep@gmail.com

Accepted 26 July 2018
D Check for updates

(c) BMJ Publishing Group Limited 2018. No commercial re-use. See rights and permissions. Published by BMJ.

To cite: Mukherjee D, Nedungadi S. BMJ Case Rep Published Online First: [please include Day Month Year]. doi:10.1136/bcr-2018226024

\section{DESCRIPTION}

Male neonate was born by normal vaginal delivery at 38 weeks. He was antenatally diagnosed to have dextrocardia, congenitally corrected transposition of great arteries, moderate ventricular septal defect and pulmonary atresia. He was born in good condition and cried at birth. However, he was noted to have saturation of $65 \%-70 \%$ in air and started on continuous positive airway pressure and transferred to neonatal intensive care unit for further monitoring. Postnatal echocardiography confirmed the diagnosis, and he was started on prostaglandin E1 (PGE1) at 5 nanogram $/ \mathrm{kg} / \mathrm{min}$.

On day 3 of life, he underwent a cardiac gated CT angiography (CTA) for further understanding of anatomy and confirmation of diagnosis. In view of need for PGE1 until transfer to tertiary cardiac surgical centre, a peripherally inserted central venous catheter was inserted in the following 12 hours. He underwent an abdominal X-ray to check long line position (figure 1).

Abdominal X-ray showed a homogenous opacity within the urinary bladder due to retention of contrast. Long line was visualised to the right. The homogenous opacity was an incidental finding when X-ray was done to confirm the long line position.

The neonate was administered intravenous iohexol 350, which is a non-ionic water soluble

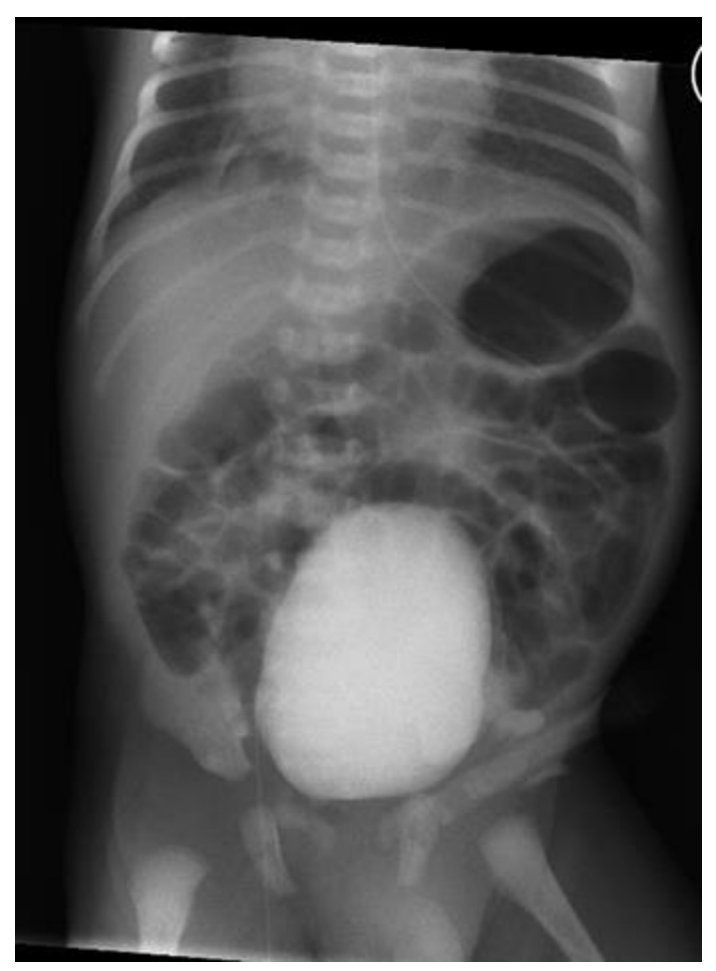

Figure 1 Homogenous dense shadow within urinary bladder.

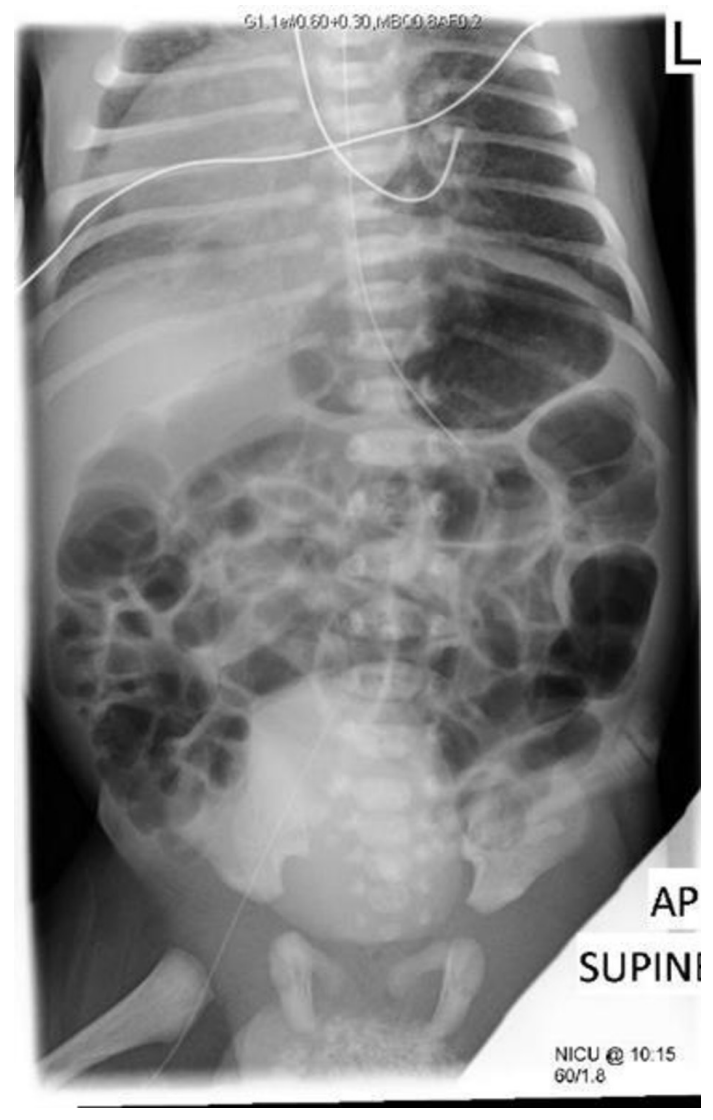

Figure 2 Normal X-ray of abdomen 6 hours later.

contrast medium. ${ }^{1}$ Iso-osmolar and hypo-osmolar contrast agents (300 mg $\mathrm{I} / \mathrm{mL}$ or greater) are preferred as they cause less adverse reactions and extravasation in children undergoing CTA. ${ }^{2}$ CTA accurately depicts the cardiac anatomy as well as the extracardiac structures in babies with complex congenital heart disease and thus serve as complimentary tools to echocardiography. ${ }^{23}$

Ninety per cent of iohexol undergoes renal excretion within the first 24 hours. Renal opacification is seen within the first minute following intravenous injection. Iohexol is also used for performing urograms. Renal failure impairs opacification of the renal tract due to decreased excretion through the kidneys and increased excretion into the small intestine through the gall bladder. This phenomenon is also noted in neonates with immature kidneys. ${ }^{1}$

Unless patients are well hydrated before the procedure, there is a likelihood of acute renal failure especially in infants and in the paediatric population. Osmotic action of the contrast further potentiates dehydration due to diuresis. ${ }^{1}$ Our patient was on maintenance intravenous fluids, and the X-ray 
repeated 6 hours after the previous showed further excretion of the contrast from the bladder (figure 2).

It is well-known fact that iodinated, non-ionic, water-soluble contrast agents are excreted by the kidneys. Contrast media-induced nephropathy has been noted in children with normal renal function. The documentation of a homogenous opacity within the urinary bladder was an incidental finding as an abdominal X-ray was done to confirm the long line tip position. We would like to highlight the need for monitoring evidence of dehydration and renal function before the administration of contrast agents to the paediatric population. ${ }^{14}$ Our patient's urea and creatinine preprocedure was $1.1 \mathrm{mmol} / \mathrm{L}$

\section{Learning points}

- Iodinated, non-ionic, water-soluble contrast agents are excreted by the kidneys.

- Babies should be adequately hydrated and their renal function should be checked before they are injected with contrast agents prior to any procedure. and $64 \mu \mathrm{mol} / \mathrm{L}$. Postprocedure urea remained the same, and creatinine was $63 \mu \mathrm{mol} / \mathrm{L}$. Urine output remained between $2 \mathrm{~mL} / \mathrm{kg} / \mathrm{h}$ and $3 \mathrm{~mL} / \mathrm{kg} / \mathrm{h}$.

Acknowledgements We acknowledge the parents of this baby who gave consent for the images to be published.

Contributors Both authors have been involved in conception and design of the article, data interpretation and writing the draft. The final draft has been approved by both authors. Both authors have been involved in patient care.

Competing interests None declared.

Patient consent Parental/guardian consent obtained.

Provenance and peer review Not commissioned; externally peer reviewed.

\section{REFERENCES}

1 https://www.accessdata.fda.gov/drugsatfda_docs/label/2015/018956s095, 020608s031 lbl.pdf

2 Dillman JR, Hernandez RJ. Role of CT in the evaluation of congenital cardiovascular disease in children. AJR Am J Roentgenol 2009;192:1219-31.

3 Tsai IC, Chen MC, Jan SL, et al. Neonatal cardiac multidetector row CT: why and how we do it. Pediatr Radiol 2008;38:438-51.

4 Ajami G, Derakhshan A, Amoozgar H, et al. Risk of nephropathy after consumption of nonionic contrast media by children undergoing cardiac angiography: a prospective study. Pediatr Cardiol 2010;31:668-73.

Copyright 2018 BMJ Publishing Group. All rights reserved. For permission to reuse any of this content visit http://group.bmj.com/group/rights-licensing/permissions.

BMJ Case Report Fellows may re-use this article for personal use and teaching without any further permission.

Become a Fellow of BMJ Case Reports today and you can:

- Submit as many cases as you like

- Enjoy fast sympathetic peer review and rapid publication of accepted articles

- Access all the published articles

- Re-use any of the published material for personal use and teaching without further permission

For information on Institutional Fellowships contact consortiasales@bmjgroup.com

Visit casereports.bmj.com for more articles like this and to become a Fellow 